\title{
PERAN RASA SYUKUR DAN DUKUNGAN SOSIAL TERHADAP KESEPIAN PADA LANJUT USIA DI PANTI WREDA
}

\author{
Sri Karina \\ Email: karinaemailku@gmail.com \\ Magister Profesi Psikologi Universitas Surabaya
}

\begin{abstract}
Elderly (elderly) is a period of late adult development. In the late adulthood,development stage occurs integrity versus despair. Often the elderly experience helplessness due to decreased physical function and limited mobility. The elderly who live in nursing homes tend to be more prone to experience loneliness because they are away from their families. This study aims to see a picture of gratitude and social support in order to reduce loneliness in the elderly in nursing homes. This study used a single case experiment design A-B with one participant. This study uses WHODAS 2.0 and UCLA Loneliness. The results obtained were that the participants could no longer function properly and could not carry out activities independently. The level of loneliness is in the medium category and the highest aspect is in the aspect of social desirability. Based on the results, the research provided 3 sessions related to gratitude and 1 session related to social support. After the intervention, it was found that gratitude and social support have an effect on reducing loneliness in the elderly in nursing homes.
\end{abstract}

Keywords: Elderly, Loneliness, Gratitude, Social Support

\begin{abstract}
Abstrak
Lansia (lanjut usia) merupakan periode perkembangan dewasa akhir. Pada masa dewasa akhir terjadi tahap perkembangan integrity versus despair. Seringkali lansia mengalami ketidakberdayaan dikarenakan menurunnya fungsi fisik dan terbatasnya mobilitas. Lansia yang tinggal di panti wreda cenderung lebih rentan mengalami kesepian karena jauh dari keluarga. Penelitian ini bertujuan untuk melihat gambaran rasa syukur dan dukungan sosial guna mengurangi kesepian pada lansia di panti wreda. Penelitian ini menggunakan single case experiment design A-B dengan satu orang partisipan. Penelitian ini menggunakan WHODAS 2.0 dan UCLA Loneliness. Hasil yang diperoleh adalah partisipan sudah tidak bisa berfungsi secara baik dan tidak bisa melakukan kegiatan secara mandiri. Tingkat kesepian berada pada kategori sedang dan aspek paling tinggi berada pada aspek social desirability. Berdasarkan hasil maka penelitan memberikan 3 sesi terkait rasa syukur dan 1 sesi terkait dukungan sosial. Setelah intervensi, diperoleh hasil bahwa rasa syukur dan dukungan sosial berpengaruh mengurangi kesepian pada lansia di panti wreda.
\end{abstract}

Kata Kunci: Lansia, Kesepian, Rasa Syukur, Dukungan Sosial

\section{PENDAHULUAN}

Penuaan merupakan proses normal dan alamiah yang dialami oleh setiap individu. Penuaan pada fase akhir dalam hidup sering disebut dengan lanjut usia (Lansia). Terdapat 5 klasifikasi lansia di Indonesia (Depkes RI dalam Maryam, 2008) yaitu pralansia, lansia, lansia risiko tinggi, lansia potensial dan lansia tidak potensial. Seseorang dengan usia 45-59 tahun disebut sebagai pralansia sedangkan usia 60 tahun lebih disebut lansia. Lansia dengan risiko tinggi ialah usia 60 tahun atau lebih yang memiliki masalah kesehatan. Lansia yang masih mampu melakukan aktivitas maupun yang aktif bekerja disebut lansia potensial. Lansia yang menggantungkan hidupnya pada orang lain karena tidak mampu lagi mencari nafkah disebut sebagai lansia tidak potensial. 
Erikson menyatakan bahwa lansia berada pada tahap perkembangan integrity versus despair (Santrock, 2012). Pada tahap ini lansia cenderung merefleksikan masa-masa yang pernah dilaluinya dan mengingat berbagai peristiwa keberhasilan maupun

ketidakberhasilannya. Beberapa lansia yang melihat berbagai peristiwa masa lalunya memilih untuk berdamai dengan peristiwa tersebut. Namun ada beberapa lansia juga yang melihat kembali masa lalunya dengan keputusasaan.

Lansia yang mengalami keputusasaan menyesali peluang penting yang hilang maupun keinginan yang tidak berhasil dicapai. Lansia seperti ini cenderung merasa tidak bahagia, tertekan, mudah marah, sering merasa sedih. Selain itu, lansia juga mengalami penurunan kondisi fisik, psikologis maupun sosial. Penurunan kondisi ini berdampak pada kesejahteraan hidup lansia.

Lansia mengalami berbagai situasi yang menimbulkan beragam perasaan dalam dirinya ketika pensiun, kebutuhan merawat, kehilangan/kematian orang terdekat, mengalami penyakit dan kehilangan kemampuan fisik (Nevid, Rathus \& Greene, 2005). Kondisi seperti ini mengakibatkan stressor pada lansia sehingga menimbulkan gangguan daya ingat, frustasi, kesepian maupun depresi (Hawari, 2011).

Lansia yang hidup sendiri lebih mengalami kesepian daripada lansia yang hidup bersama orang lain (Routasalo et al dalam Santrock, 2002). Keluarga yang tidak mampu untuk mengurus orangtua ataupun kerabatnya yang lansia dikarenakan sibuk dengan pekerjaan ataupun tidak menemukan solusi dengan pasangan sehingga dititipkan ke Panti Wreda. Adapula lansia yang tinggal di Panti Wreda dikarenakan keinginan diri sendiri. Hal ini mereka jalani karena merasa dirinya membebani anak ataupun keluarga.

Berdasarkan temuan peneliti, lansia yang tinggal di Panti Wreda cenderung merasakan diabaikan oleh keluarga karena kurangnya atau bahkan hampir tidak merasakan interaksi bersama keluarga lagi. Perselisihan dengan rekan sesama lansia ataupun perawat di panti wreda juga membuat ketidaknyamanan. Kondisi fisik yang mengalami penurunan juga membuat mobilitas berkurang dan merasa diri tidak berguna. Panti wreda memberikan jadwal rutin dengan aktivitas beragam pada lansia untuk memanfaatkan waktu yang ada. Walaupun panti wreda memberikan beberapa aktivitas pada lansia, namun hal ini kurang bisa diikuti oleh lansia yang resiko tinggi. Hidup 
mereka setiap harinya bergantung pada pertolongan orang lain serta tidak mampu memberikan kontribusi pada lingkungan. Kurangnya kemampuan diri untuk bisa terlibat memberikan dampak kesepian pada lansia.

Kesepian merupakan kondisi mental dan emosional yang merasa terasingkan dan kurang memiliki hubungan yang bermakna dengan orang lain (Bruno dalam Basuki, 2015). Lansia yang mengalami kesepian cenderung merasa tidak memiliki hubungan yang baik dengan orang lain. Mereka merasa ditinggalkan, merasa tidak ada seorang pun yang memahami, dan tidak ada seorang pun yang bisa ia andalkan.

Baron dan Byrne (2006) menyatakan kesepian mengakibatkan seseorang tidak bahagia dan tidak merasa puas dengan diri sendiri. Kesepian juga mengakibatkan seseorang cenderung tidak mau membuka diri, putus asa dan merasa sia-sia. Myers (2012) mengatakan bahwa kesepian berdampak pada hilangnya kepercayaan pada orang lain sehingga menampakkan rasa pesimis ketika terlibat dalam relasi, kurang tertarik pada lawan bicara.

Kesepian pada lansia dikarenakan berkurangnya kegiatan dalam merawat anak, berkurangnya kerabat, berkurangnya aktifitas yang mengakibatkan banyaknya waktu luang, meninggalnya pasangan hidup, anak yang sudah bekerja dan memiliki keluarga. Beberapa faktor penyebab kesepian juga diungkapkan melalui penelitian yang dilakukan Novitasari dan Aulia (2019) yaitu tidak adanya orang terdekat yang mau tinggal bersama, tidak adanya kehadiran teman untuk bisa saling bercerita, terbatasnya hubungan dengan keluarga maupun kerabat, ketidakmampuan fisik untuk bisa terlibat dalam kegiatan komunitas.

Kesepian tidak hanya berdampak pada kesehatan mental namun juga pada kesehatan fisik. Kesepian mengakibatkan penurunan daya tahan tubuh, kurangnya kualitas tidur, kecemasan, depresi hingga keinginan untuk bunuh diri. Kesepian dapat diatasi bila seseorang menerapkan strategi koping yang positif. Strategi koping yang dapat dilakukan lansia untuk mengatasi kesepian yaitu refleksi diri, mendapat dukungan sosial, religiusitas, kedekatan relasi, aktivitas keseharian, penerimaan diri (Sønderby, 2013).

Rasa syukur (gratitude) merupakan bentuk emosi positif yang dapat memelihara hubungan sosial, meningkatkan well-being, meningkatkan kesehatan fisik dan mengurangi kesepian (Barlett \& Arpin, 2019). Rasa syukur (gratitude) merupakan suatu emosi positif seseorang yang ditunjukkan melalui sikap 
dan nilai yang dipahami sebagai bentuk rasa terimakasih pada Tuhan atas segala sesuatu yang diterimanya. Rasa syukur berpengaruh pada kesejahteraan seseorang dalam hidupnya. Menurut Emmons \& McCullough (dalam Prabowo 2017) menyatakan bahwa rasa syukur (gratitude) membuat seseorang bijaksana ketika menghadapi situasi yang terjadi sedangkan seseorang yang kurang memiliki rasa syukur maka akan terjadi ketidakharmonisan pada dirinya bersama lingkungan yang ada.

\section{METODE PENELITIAN}

Metode penelitian yang dipakai adalah single case experiment design A-B yang merupakan bentuk eksperimen dengan sedikit subjek dan menganalisisnya secara individual serta memiliki satu baseline phase dan satu treatment phase. Terdapat dua kondisi yang ada yaitu baseline phase dan treatment phase. Baseline phase merupakan kondisi awal sebelum diberikan treeatment sedangkan treatment phase merupakan kondisi yang telah diberikan treatment (Yuwanto, 2019).

Penelitian ini melibatkan satu orang partisipan berusia 71 tahun yang tinggal di Panti Wreda. Partisipan ialah seorang wanita yang sudah tinggal di Panti Wreda selama 4 bulan. Partisipan termasuk dalam kategori lansia resiko tinggi, sehari-hari duduk di kursi roda. Penelitian ini berlangsung selama kurang lebih 2 bulan.

Wawancara dan observasi juga dilakukan dalam penelitian ini. Wawancara dilakukan pada partisipan, rekan satu ruangan (dua orang nenek) di panti wreda, satu orang perawat juga seorang kerabat partisipan (keponakan). Hal ini dilakukan guna mendapatkan gambaran tentang partisipan sebelum tingal di Panti Wreda maupun setelah tinggal di Panti Wreda.

Observasi dilakukan seminggu dua kali dengan durasi waktu 1,5 jam. Observasi dilakukan oleh peneliti dengan mengamati aktivitas partisipan, interaksi partisipan serta sikap lingkungan terhadap keberadaan partisipan. Data observasi digunakan untuk pengisian WHODAS 2.0. Pengisian WHODAS 2.0 dilakukan untuk mengukur tingkat kesehatan partisipan dalam keberfungsian kognisi, mobilitas, perawatan diri, pergaulan, aktivitas hidup, serta partisipasi dalam lingkungan sosial.

Partisipan juga diberikan UCLA Loneliness guna mengukur taraf kesepian. Selama proses pengisian, peneliti membantu membacakan pertanyaan untuk partisipan dikarenakan kondisi penglihatan yang sudah berkurang. 
Intervensi yang diberikan pada partisipan adalah dengan melatih rasa syukur (gratitude). Selain itu diberikan pula reflective listening. Reflective listening dengan mendengarkan lagu maupun renungan spiritual melalui media radio. Selain itu, peneliti mengajarkan partisipan dalam menghafalkan sebuah lagu berirama riang, juga mengajak partisipan berbincang bersama rekan satu ruangan.

Tabel 1. Faktor pendukung dan Penghambat

\begin{tabular}{|c|c|c|}
\hline & $\begin{array}{l}\text { Faktor } \\
\text { Pendukung }\end{array}$ & $\begin{array}{l}\text { Faktor } \\
\text { Penghambat }\end{array}$ \\
\hline Internal & $\begin{array}{l}\text { - Senang } \\
\text { melakukan } \\
\text { aktivitas } \\
\text { kerohanian } \\
\text { - Memiliki } \\
\text { pendengaran } \\
\text { yang masih } \\
\text { berfungsi } \\
\text { baik. }\end{array}$ & $\begin{array}{lr}\text { - } & \text { Sangat } \\
\text { bergantung } \\
\text { pada bantuan } \\
\text { orang lain } \\
\text { dalam } \\
\text { melakukan } \\
\text { aktivitas } \\
\text { keseharian } \\
\text { karena kondisi } \\
\text { fisik yang } \\
\text { menurun. } \\
\text { - Sulit untuk } \\
\text { melihat risi } \\
\text { positif orang } \\
\text { lain } \\
\text { perisitiwa yang } \\
\text { ia alami. }\end{array}$ \\
\hline Eksternal & $\begin{array}{l}\text { - Rutinitas } \\
\text { yang } \\
\text { dilakukan } \\
\text { setiap hari } \\
\text { ialah doa } \\
\text { - Seorang } \\
\text { rekan satu } \\
\text { ruangan } \\
\text { yang } \\
\text { berperawaka } \\
\text { n ramah, } \\
\text { mulai } \\
\text { mengajak } \\
\text { berbincang- } \\
\text { bincang. }\end{array}$ & $\begin{array}{l}\text { - Perawat kurang } \\
\text { melakukan } \\
\text { interaksi. } \\
\text { - Kurang } \\
\text { memiliki } \\
\text { aktivitas yang } \\
\text { beragam karena } \\
\text { tidak bisa } \\
\text { melakukannya } \\
\text { sendiri. }\end{array}$ \\
\hline
\end{tabular}

Berdasarkan tabel diatas maka intervensi dilakukan sesuai dengan faktor pendukung dan penghambat sehingga dapat lebih mudah diterapkan. Penelitian ini memberikan 4 sesi yang dilakukan selama 2 minggu. Sesi pertama membantu partisipan menghitung hal baik yang sudah terjadi selama masa hidupnya (counting blessing) dan membantu untuk bisa mengucapkan rasa syukur pada peristiwa yang berhasil ia lalui (creating $a$ gratitude). Kemudian, membantu partisipan untuk mengingat hal kecil yang ia bisa syukuri setiap harinya (appreciating small thing). Pada sesi ketiga, partisipan diajak untuk bisa mengikhlaskan kejadian di masa lalu yang belum bisa ia capai (taking for granted), menemukan hal yang bisa disyukuri melalui peristiwa tak terduga (discovering unexpected gratitude). Sesi keempat, partisipan diajak mengisi waktu luangnya dengan bernyanyi (pleasant event schedule- reflective listening) dan menjalin percakapan dengan rekan satu ruangan, perawat dan keluarga (pleasant having a schedule-having a conversation).

\section{HASIL DAN PEMBAHASAN}

Hasil yang ditemukan dari
pengukuran yang diberikan pada
partisipan diperoleh dari data WHODAS 2.0 dan UCLA Loneliness. Berdasarkan temuan yang diperoleh dari WHODAS 2.0 
diperoleh data bahwa partisipan tidak dapat berfungsi secara baik. Partisipan meiliki keterbatasan dalam memahami dan berkomunikasi, cenderung sukar untuk berkonsentrasi. Partisipan tidak bisa melakukan mobilitas dan hanya bergantung pada pertolongan orang lain dan kursi roda. Ketidakmampuan partisipan dalam melakukan aktivitas secara mandiri membuatnya juga susah untuk melakukan perawatan diri (mandi, mengambil makan, berpakaian) berpindah tempat). Partisipan masih bisa menyendokkan makanan sendiri, menyisir rambut. Partisipan masih dapat berkomunikasi dengan jelas.

Hasil dari ULCA Loneliness yang diberikan pada partisipan ialah pada skor 53. Skor yang didapat kemudian dicek kedalam table kategori UCLA Loneliness.

\section{Tabel 2. Kategori ULCA Loneliness}

\begin{tabular}{|l|l|}
\hline SKALA & KATEGORI \\
\hline $23-34$ & Tidak kesepian \\
\hline $35-49$ & Kesepian rendah \\
\hline $50-64$ & Kesepian sedang \\
\hline $65-80$ & Kesepian berat \\
\hline
\end{tabular}

Berdasarkan tabel UCLA Loneliness diatas, maka skor 53 menunjukkan bahwa partisipan mengalami kesepian pada kategori sedang. Hasil yang paling tinggi terdapat pada aspek social desirability (keinginan kehidupan sosial dalam kehidupan seharihari). Kesepian sosial muuncul karena hilangnya kedekatan juga tidak terpenuhinya kebutuhan menjalin komunikasi dengan keluarga dan oranglain.

Kondisi awal, partisipan merupakan seorang yang membutuhkan waktu yang cukup lama untuk menjalin kedekatan dengan orang yang baru dikenal. Setelah 3 minggu menjalin rapport, maka diperoleh data sebagai berikut: sering mengeluhkan keberadaan orang disekitarnya yang ia rasa tidak bisa ia andalkan dan kurang memperhatikannya. Selain itu, partisipan sering melamun dan tidak mau menjalin komunikasi dan kedekatan dengan rekan satu ruangannya. Beberapakali sering menangis ketika bercerita mengenai masa lalu dan tidak betah berada di panti wreda.

Setelah dilakukan intervensi selama 2 minggu, partisipan sudah mulai terbiasa untuk mengucapkan rasa syukur. Walaupun masih sukar untuk bisa menemukan rasa syukur pada peristiwa yang belum ia capai maupun dari hal tak terduga.

Rasa syukur yang perlahan sudah mulai bisa diucapkan ataupun dirasakan berdampak pula pada tumbuhnya perasaan untuk mau menjalin komunikasi dengan orang lain, mudah membalas sapaan dan memberikan senyuman. Komunikasi yang terjalin tidak hanya dengan rekan satu ruangan tetapi dengan perawat dan 
keluarga. Pihak keluarga diberikan gambaran mengenai keadaan partisipan. Hal tersebut membuat keluarga mulai rutin menjenguk. Partisipan juga sudah mulai menerima keadaannya saat ini dan sudah tidak sering minta pulang ke rumah. Individu yang merasa bersyukur lebih termotivasi menjalin relasi karena mendapatkan pandangan yang positif dari hubungan tersebut. Hal ini berpengaruh terhadap rendahnya tingkat kesepian seseorang (Bartlett \& Arpin, 2019).

\section{PENUTUP}

Berdasarkan hasil penelitian maka diperoleh kesimpulan bahwa rasa syukur dan dukungan sosial dapat menurunkan kesepian pada lansia di panti wreda. Pemberian intervensi memerlukan waktu lebih dari 2 minggu dikarenakan partisipan yang membutuhkan waktu untuk bisa memahami. Lansia yang kurang berfungsi secara maksimal cenderung lebih mengalami kesepian. Hal ini membutuhkan perhatian dari lingkungan sosial guna mengurangi kesepian.

Saran untuk penelitian selanjutnya agar melaksanakan intervensi dengan waktu yang lebih lama dengan mempertimbangkan karakteritik partisipan. Selain itu, penelitian selanjutnya agar mengembangkan intervensi lainnya terkait mengurangi kesepian pada lansia.

\section{DAFTAR PUSTAKA}

Baron, R.A., \& Byrne, D. 2006. Social Psychology. Boston: Pearson Education, Inc.

Bartlett, M. Y., \& Arpin, S. N. 2019. Gratitude and Loneliness: Enchancing Health and Well-Being in Older Adults. Research on Aging, 41(8), 772-793.

Basuki,W. 2015. Faktor-faktor penyebab kesepia terhadap tingkat depresi pada lansia penghuni panti sosial Tresna Werdha Nirwana Puri Kota Samarinda. eJournal Psikologi, 4 (1), 713-730.

Hawari, D. 2011. Manajemen Stres Cemas dan Depresi. Jakarta: FKUI.

Maryam, R. S., Ekasari, M. F., Rosidawati., Jubaedi, A., \& Batubara, I. 2008. Mengenal Usia Lanjut dan Perawatannya. Jakarta: Penerbit Salemba Medika.

Myers, D. G. 2012. Social Psychology. Jakarta: Salemba Humanika

Nevid, J. S., Rathus, S. A., \& Greene, B. 2005. Pengantar Psikologi Abnormal. Jakarta: Penerbit Erlangga.

Novitasari, R., Aulia, D. 2019. Kebersyukuran dan Kesepian pada Lansia yang Menjadi Janda/Duda. Jurnal Ilmiah Psikologi Terapan, 7(2),146-175.

Prabowo, A. 2017. Gratitude dan Psychological Well-being pada Remaja. Jurnal Ilmiah Psikologi Terapan, 5(2), 260-270. 
Santrock, J. W. 2002. Life-Span Development. Jakarta: Penerbit Erlangga.

Santrock, J. W. 2012. Life-Span Develoment Perkembangan Masa Hidup. Jakarta: Penerbit Erlangga.

Sønderby, L. C. 2013. Loneliness: An Integrative Approach. Journal of Integrated Social Sciences, (3(1), 129.

Yuwanto, L. 2019. Metode Penelitian Eksperimen. Yogyakarta: Graha Ilmu. 